\title{
Is a reduced estimated glomerular filtration rate a risk factor for stroke in patients with type 2 diabetes?
}

\author{
Ryotaro Bouchi, Tetsuya Babazono, Izumi Nyumura, Kiwako Toya, Toshihide Hayashi, Mari Ohta, Ko Hanai, \\ Yuka Kiuchi, Kumi Suzuki and Yasuhiko Iwamoto
}

\begin{abstract}
Although chronic kidney disease is a risk factor for cardiovascular disease it is unclear whether diabetic patients with a reduced glomerular filtration rate (GFR), independent of (micro)albuminuria, carry an increased risk of stroke. We therefore investigated the independent effect of estimated GFR (eGFR) on stroke events in patients with type 2 diabetes mellitus (T2DM). We studied T2DM patients with an eGFR $\geqslant 15 \mathrm{ml} \mathrm{min}^{-1}$ per $1.73 \mathrm{~m}^{2}$, who had no history of stroke. Patients were divided into four categories by the eGFR at baseline for comparison: $\geqslant 90,60-89,30-59$ and $15-29 \mathrm{ml} \mathrm{min}^{-1}$ per $1.73 \mathrm{~m}^{2}$. The end point was an incident stroke event. The Cox proportional hazard model was used to calculate the hazard ratio (HR) and $95 \%$ confidence interval (CI). The study included a total of 1300 T2DM patients (546 women and 754 men) with a mean ( \pm s.d.) age of $63 \pm 13$ years. During a mean follow-up period of $3.7 \pm 1.4$ years, 91 patients experienced an incident stroke event. Although a lower eGFR was associated with an increased stroke risk using a univariate model, statistical significance disappeared after adjusting for other risk factors including albuminuria. The $\mathrm{HR}(95 \% \mathrm{Cl})$ was $0.75(0.40-1.41, P=0.373), 0.99(0.50-1.95$, $P=0.964)$ and $0.91(0.36-2.28, P=0.844)$ for patients with eGFRs of $60-89,30-59$ and $15-29 \mathrm{ml} \mathrm{min}^{-1}$ per $1.73 \mathrm{~m}^{2}$, respectively, compared with patients with an eGFR $\geqslant 90$. Clinical albuminuria remained a significant risk factor for stroke, and the adjusted HR compared with normoalbuminuria was 2.40 (1.46-3.95, $P=0.001)$. In conclusion, the association between reduced GFR and stroke events in patients with T2DM is likely to be mediated by albuminuria.
\end{abstract}

Hypertension Research (2009) 32, 381-386; doi:10.1038/hr.2009.30; published online 27 March 2009

Keywords: albuminuria; diabetes; estimated glomerular filtration rate; stroke

\section{INTRODUCTION}

Chronic kidney disease $(\mathrm{CKD})^{1}$ has been recognized as an independent risk factor for cardiovascular disease mortality and morbidity in both Japanese ${ }^{2}$ and Western populations. ${ }^{3,4}$ The incidence of coronary heart disease and stroke differs between Western and Asian populations; ${ }^{5}$ in Japan the stroke mortality is three-fold higher than in the United States, whereas coronary heart disease mortality is approximately one-third that in the United States. ${ }^{6}$ The role of CKD in the pathogenesis and progression of stroke may therefore differ by ethnicity.

Diabetes is a strong risk factor for coronary heart disease as well as stroke. The hazard ratio (HR) of stroke in patients with type 2 diabetes mellitus (T2DM) is reported to be two- to five-fold that in the nondiabetic population. ${ }^{7,8}$ In addition, the progression of diabetic nephropathy is associated with a higher incidence of cardiovascular diseases. A decreased estimated glomerular filtration rate (eGFR) has also been shown to be a new and independent risk factor for cardiovascular events and all-cause mortality in patients with $\mathrm{T} 2 \mathrm{DM} ;{ }^{9}$ however, evidence is lacking regarding whether or to what extent reduced eGFRs increase the risk of incident stroke events in diabetic patients. We therefore examined whether eGFR could predict the risk of stroke, independent of conventional cardiovascular risk factors and albuminuria in T2DM patients.

\section{METHODS}

Study population

This was a prospective hospital-based observational cohort study that included consecutive patients with T2DM who were admitted to the Department of Medicine, Diabetes Center, Tokyo Women's Medical University Hospital in Tokyo, Japan, from 1 January 2002 to 31 December 2003, for the purpose of glycemic control and evaluation of diabetic complications. Patients were eligible if they were 20 years old or older, had no history of stroke and had an eGFR $\geqslant 15 \mathrm{ml} \mathrm{min}^{-1}$ per $1.73 \mathrm{~m}^{2}$. Patients undergoing renal replacement therapy, pregnant women and patients with infectious and/or malignant diseases were excluded. The diagnosis of T2DM was made according to the criteria of the World Health Organization (WHO).$^{10}$

On admission (referred to as the baseline for the present investigation), participants underwent a routine medical history, physical examination and blood sampling. Information regarding smoking and family history of stroke was obtained using a standard questionnaire. Smoking habit was classified either as currently smoking or not currently smoking. Physical examination 
included blood pressure measurement and anthropometry, and laboratory examinations included hemoglobin A1C (A1C), serum lipids and creatinine levels using fasting blood samples, as well as urinary albumin excretion measured in the first morning urine specimen.

Clinical evidence of coronary artery disease (CAD) was defined as the presence of angina pectoris diagnosed by coronary angiography or myocardial scintigraphy, a history of myocardial infarction or previous coronary revascularization. A past history of peripheral artery disease (PAD) was defined as lower extremity PAD, according to the 2005 guidelines of the American College of Cardiology/American Heart Association. ${ }^{11}$

\section{Measurements}

Serum creatinine was initially measured in the hospital laboratory using Jaffe's method. In January 2003, Jaffe's method was replaced by an enzymatic method. Serum creatinine concentrations obtained after January 2003 were therefore adjusted using the following regression equation, which was obtained from a correlational analysis between both measurements of serum creatinine analysis in 10132 samples from diabetic patients: serum creatinine (enzymatic method, mg per $100 \mathrm{ml}$ ) $=0.972 \times$ serum creatinine (Jaffe's method, mg per $100 \mathrm{ml})-0.224(r=0.9992, P<0.001)$. The GFR was estimated using the equation that originated from the Modification of diet in renal disease (MDRD) Study group equation, ${ }^{12}$ refitted for Japanese individuals: ${ }^{13}$ $\mathrm{GFR}=175 \times \mathrm{SCr}^{-1.154} \times \mathrm{age}^{-0.203} \times 0.742([$ if female $] \times 0.741)$, where $\mathrm{SCr}=$ serum creatinine measured by enzymatic methods in $\mathrm{mg}$ per $100 \mathrm{ml}$. Patients were divided into the following four categories by eGFR at baseline: $\geqslant 90,60-89,30$ 59 and $15-29 \mathrm{ml} \mathrm{min}^{-1}$ per $1.73 \mathrm{~m}^{2}$.

Classification of the degree of urinary albumin excretion was assessed according to the American Diabetes Association (ADA) criteria ${ }^{14}$ on the basis of albumin-to-creatinine ratio (ACR) in the first morning urine specimen. Urinary ACR was calculated from urinary albumin, determined using the latex agglutination method and urinary creatinine concentration. Patients were classified into one of the following three categories: normoalbuminuria if the ACR was less than $30 \mathrm{mg}$ per $\mathrm{g} \mathrm{Cr}$, microalbuminuria if the ACR was 30-299 mg per g Cr, or clinical albuminuria if the ACR was equal to or greater than $300 \mathrm{mg}$ per $\mathrm{g} \mathrm{Cr}$.

$\mathrm{A} 1 \mathrm{C}$ was determined by high-performance liquid chromatography (normal range: $4.3 \%-5.8 \%$ ). Total cholesterol and high-density lipoprotein (HDL) cholesterol were determined enzymatically. Low-density lipoprotein (LDL) cholesterol was calculated using the Friedewald equation when the plasma triglyceride level was less than $400 \mathrm{mg}$ per $100 \mathrm{ml}$.

\section{Outcomes}

Patients were followed until September 2007. The primary end point was an incident first stroke event, the information regarding which was obtained by direct reference to medical records by a single investigator (R.B.). Stroke was defined as an acute focal neurological deficit lasting for longer than $24 \mathrm{~h}$ or resulting in death within $24 \mathrm{~h}$ of the onset of symptoms, which was diagnosed as attributable to a cerebral lesion of vascular origin [International Classification of Diseases, 9th Revision (ICD-9), codes of cerebrovascular diseases]. Most stroke cases were diagnosed by computed tomography, magnetic resonance imaging, including diffusion image and magnetic resonance angiography of the brain, and carotid duplex imaging.

\section{Statistical analyses}

Data were expressed as percentages, arithmetic means \pm standard deviation (s.d.) or geometric means with a 95\% confidence interval (CI) depending on the distribution of the data. Triglycerides, ACR and C-reactive protein (CRP) were logarithmically transformed because of skewed distributions. For statistical analyses, a one-way ANOVA was used for between-group comparisons for continuous variables and the Cochran-Armitage test was used for categorical variables. Kaplan-Meier curves were used to construct the cumulative incidence of stroke. The Cox proportional hazard model was used to estimate the HR and the 95\% confidence interval (CI). All statistical analyses were performed using the Statistical Analysis System (SAS Institute, Cary, NC, USA), version 9.13. A $P$-value less than 0.05 was considered statistically significant.

\section{RESULTS}

A total of 1300 T2DM patients were enrolled between 2002 and 2003. The study included 546 women and 754 men, with a mean $( \pm$ s.d.) age of $63 \pm 13$ years (range $=21-92$ years). At baseline, the mean eGFR was $70.7 \pm 28.6 \mathrm{ml} \mathrm{min}^{-1}$ per $1.73 \mathrm{~m}^{2}$ (range $=15.4-155.5 \mathrm{ml} \mathrm{min}^{-1}$ per $1.73 \mathrm{~m}^{2}$ ). A total of $290,567,335$ and 108 diabetic patients were classified into the following eGFR-specific categories: $\geqslant 90,60-89,30$ 59 and $15-29 \mathrm{ml} \mathrm{min}^{-1}$ per $1.73 \mathrm{~m}^{2}$, respectively. Demographic and characteristic data regarding patients in the four eGFR categories are listed in Table 1. Compared with patients with an eGFR $\geqslant 90$, patients with an eGFR $<90 \mathrm{ml} \mathrm{min}^{-1}$ per $1.73 \mathrm{~m}^{2}$ were likely to be older and to have a longer duration of diabetes and higher systolic but lower diastolic blood pressure, yielding higher pulse pressure. Furthermore, a decreased level of eGFR was significantly associated with a higher prevalence of diabetic retinopathy, CAD and PAD. Medications and laboratory data by eGFR categories are shown in Table 1 and Table 2, respectively.

During a mean follow-up period of $3.7 \pm 1.4$ years (median $=4.0$ years; maximum $=5.5$ years; overall $=4784$ patient-years), 91 first episodes of stroke were observed, yielding an incidence rate of 19.0 episodes per 1000 patient-years. We observed 77 stroke cases with cerebral infarction, 13 with cerebral bleeding and one with a subarachnoid hemorrhage.

As shown in Figure 1a, the 5-year cumulative incidence of stroke in patients with eGFRs $\geqslant 90,60-89,30-59$ and $15-29 \mathrm{ml} \mathrm{min}^{-1}$ per $1.73 \mathrm{~m}^{2}$ was $7.0 \%, 7.9 \%, 14.7 \%$ and $15.5 \%$, respectively $(P=0.001$ by log-rank test). Using a univariate Cox model (Figure 2a), the HRs of strokes for patients with eGFRs of 30-59 (2.35, 95\% CI=1.28-4.30, $P=0.006)$ and $15-29 \mathrm{ml} \mathrm{min}^{-1}$ per $1.73 \mathrm{~m}^{2}(2.43,95 \% \mathrm{CI}=1.12-5.29$, $P=0.025)$ were significant compared with patients with an eGFR $\geqslant 90 \mathrm{ml} \mathrm{min}^{-1}$ per $1.73 \mathrm{~m}^{2}$.

In the multivariate Cox model analysis, the following variables were incorporated as candidates for explanatory variables: age, gender, body mass index, family history of stroke, smoking status, systolic and diastolic blood pressure, duration of diabetes, proliferative diabetic retinopathy, logarithmically transformed triglycerides, HDL/LDL cholesterol level, A1C, logarithmically transformed CRP, use of reninangiotensin system blockers and antiplatelet medication, and logarithmically transformed urinary ACR. Stepwise selection was then applied to limit and indicate co-variables with a significant effect, selecting age (HR 1.06, 95\% CI=1.03-1.08, $P<0.001$ ), current smoking status (HR 1.67, 95\% CI=1.02-2.75, $P=0.042$ ), atrial fibrillation (HR 1.99, 95\% CI=1.01-3.92, $P=0.048$ ) and LDL cholesterol (HR $1.01,95 \% \mathrm{CI}=1.00-1.01, P=0.022)$ as the final covariates. After adjusting for these significant variables, the significance of the HRs observed in the univariate analysis for patients with eGFRs of 30-59 and $15-29 \mathrm{ml} \mathrm{min}^{-1}$ per $1.73 \mathrm{~m}^{2}$ disappeared (Figure $2 \mathrm{~b}$ ).

When participants were classified by urinary ACR at baseline (Figure 1b), the 5-year cumulative incidence of stroke in patients with normoalbuminuria, microalbuminuria and clinical albuminuria was $7.3 \%, 10.2 \%$ and $16.6 \%$, respectively ( $P=0.0003$ by log rank test). The HR of stroke events for patients with microalbuminuria (1.69, $95 \% \mathrm{CI}=1.01-2.83, P=0.047, N=323)$ and clinical albuminuria (2.62, $95 \% \mathrm{CI}=1.61-4.24, P<0.001, N=279)$ was significant in the univariate Cox model analysis when compared with patients with normoalbuminuria $(N=698)$ (Figure 3a). In the multivariate Cox model that included the covariates listed above, but using eGFR instead of urinary ACR (Figure 3b), the HR for patients with clinical albuminuria remained significant $(2.40,95 \%$ CI 1.46-2.40, $P<0.001)$. The significance found in patients with microalbuminuria, however, disappeared (1.41, 95\% CI 0.83-2.37, $P=0.202$ ). 
Table 1 Patients' characteristics and medications according to eGFR levels at baseline

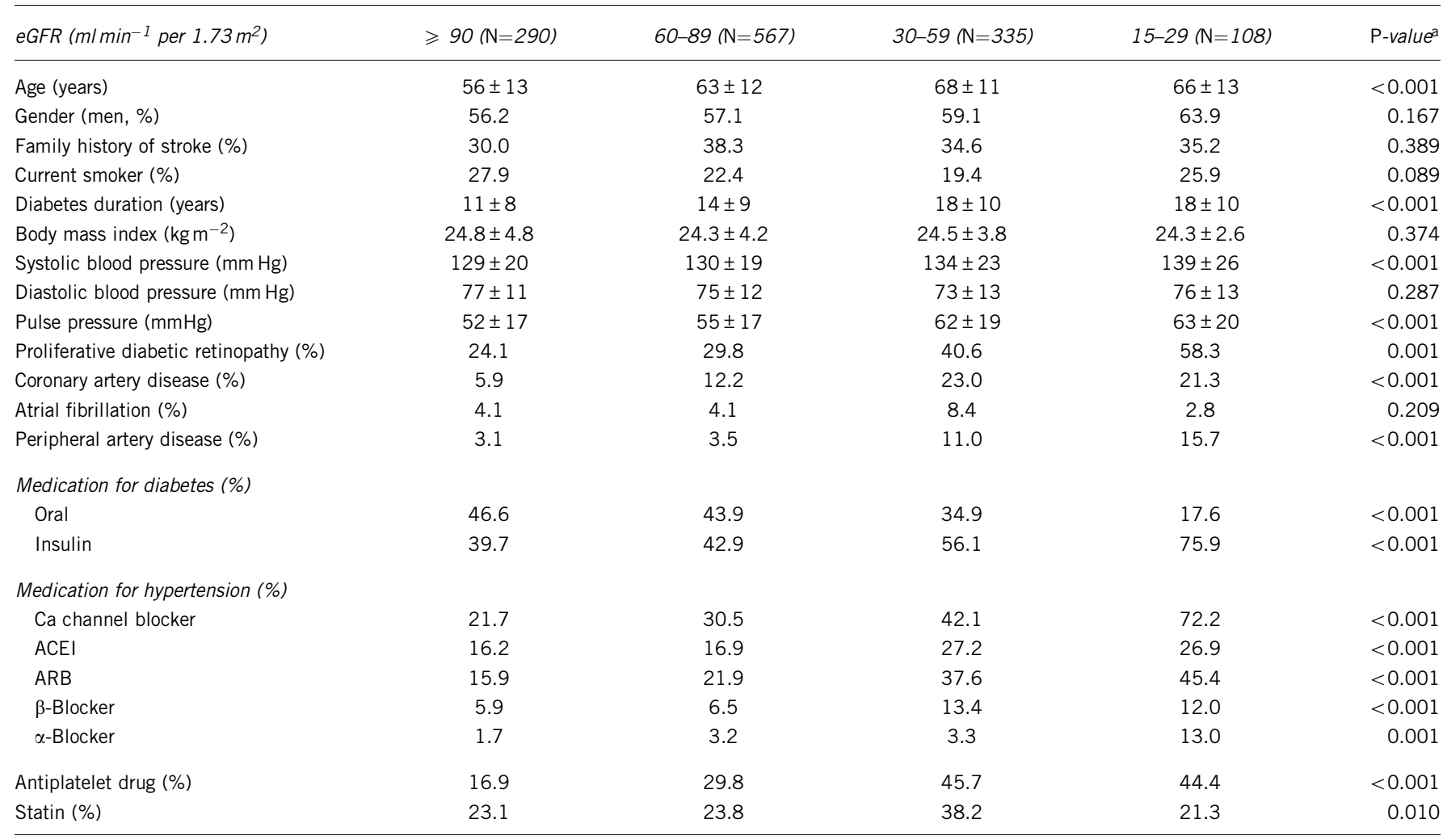

Abbreviations: ACEI, angiotensin-converting enzyme inhibitor; ARB, angiotensin type 1 receptor blocker; eGFR, estimated glomerular filtration rate.

Data are expressed as mean \pm s.d. or percentage.

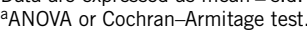

Table 2 Laboratory data according to eGFR levels at baseline

\begin{tabular}{|c|c|c|c|c|c|}
\hline eGFR $\left(\mathrm{m} / \mathrm{min}^{-1}\right.$ per $\left.1.73 \mathrm{~m}^{2}\right)$ & $\geqslant 90(N=290)$ & $60-89(N=567)$ & $30-59(N=335)$ & $15-29(N=108)$ & P-value ${ }^{a}$ \\
\hline $\mathrm{A} 1 \mathrm{C}(\%)$ & $9.1 \pm 1.9$ & $8.6 \pm 1.6$ & $8.3 \pm 1.8$ & $7.5 \pm 1.7$ & $<0.001$ \\
\hline Triglyceride (mg per $100 \mathrm{ml})^{\mathrm{b}}$ & $117(111-125)$ & $120(115-125)$ & $139(131-147)$ & 135 (124-147) & 0.075 \\
\hline HDL cholesterol (mg per $100 \mathrm{ml}$ ) & $49 \pm 15$ & $48 \pm 14$ & $46 \pm 15$ & $41 \pm 19$ & $<0.001$ \\
\hline LDL cholesterol (mg per 100 ml) & $116 \pm 35$ & $115 \pm 31$ & $119 \pm 38$ & $115 \pm 45$ & 0.536 \\
\hline $\mathrm{CRP}\left(\left.m g\right|^{-1}\right)^{\mathrm{b}}$ & $0.94(0.83-1.07)$ & $0.96(0.88-1.04)$ & $1.35(1.21-1.52)$ & $1.75(1.41-2.18)$ & $<0.001$ \\
\hline Hemoglobin (g per $100 \mathrm{ml}$ ) & $13.9 \pm 1.6$ & $13.7 \pm 1.6$ & $12.7 \pm 1.6$ & $10.8 \pm 2.0$ & $<0.001$ \\
\hline $\mathrm{ACR}(\mathrm{mg} \text { per g } \mathrm{Cr})^{\mathrm{b}}$ & $22(19-26)$ & $25(22-29)$ & $93(74-118)$ & $842(610-1163)$ & $<0.001$ \\
\hline$<30(\%)$ & 67.9 & 65.4 & 36.7 & 6.5 & $<0.001$ \\
\hline 30-299 (\%) & 26.9 & 24.2 & 28.1 & 13.0 & 0.128 \\
\hline$\geqslant 300(\%)$ & 5.2 & 10.4 & 35.2 & 80.6 & 0.047 \\
\hline Serum creatinine (mg per $100 \mathrm{ml}$ ) & $0.53 \pm 0.10$ & $0.72 \pm 0.12$ & $1.06 \pm 0.22$ & $2.33 \pm 0.72$ & $<0.001$ \\
\hline eGFR $\left(\mathrm{ml} \mathrm{min}-1\right.$ per $\left.1.73 \mathrm{~m}^{2}\right)$ & $108.7 \pm 20.4$ & $74.4 \pm 8.5$ & $47.8 \pm 8.5$ & $20.7 \pm 5.5$ & $<0.001$ \\
\hline
\end{tabular}

Abbreviations: ACR, albumin-to-creatinine ratio; CRP, C-reactive protein; eGFR, estimated glomerular filtration rate; HDL/LDL, high/low-density lipoprotein.

Data are expressed as mean \pm s.d., geometric mean $(95 \% \mathrm{CI})$ or percentage.

aNOVA or Cochran-Armitage test.

bGeometric mean.

Finally, HRs were calculated for six groups classified according to eGFRs $\geqslant 60 \mathrm{ml} \mathrm{min}^{-1}$ per $1.73 \mathrm{~m}^{2}$ or less and the degree of albuminuria to simultaneously determine the effects of these two renal manifestations on stroke events. The group with an eGFR $\geqslant 60 \mathrm{ml} \mathrm{min}^{-1}$ per $1.73 \mathrm{~m}^{2}$ and normoalbuminuria was defined as the reference group. The impact of reduced eGFR on stroke was observed only in patients with clinical albuminuria, whereas a stepwise increase in HRs was identified as albuminuria increased, regardless of eGFR levels at baseline (Figure 4).

\section{DISCUSSION}

Although CKD has recently been identified as a serious risk factor for cardiovascular events, including stroke, ${ }^{3,9,15}$ the independent effects of manifestations of CKD, albuminuria and reduced GFR have been largely unknown, especially in diabetic patients who carry a particularly high risk of developing stroke. To the best of our knowledge, this is the first study to determine the independent effect of eGFRs on the incidence of stroke events in T2DM patients, irrespective of the albuminuria levels. In this large hospital-based prospective cohort 
a

\begin{tabular}{lcccccc} 
No. at risk & \multicolumn{7}{c}{ Time (years) } \\
eGFR $\geq 90$ & 290 & 278 & 255 & 232 & 175 & 60 \\
eGFR $60-89$ & 567 & 524 & 489 & 452 & 309 & 84 \\
eGFR 30-59 & 335 & 301 & 265 & 240 & 248 & 41 \\
eGFR 15-29 & 108 & 94 & 78 & 63 & 49 & 13
\end{tabular}

eGFR15-29 mL/min/1.73 $\mathrm{m}^{2}$

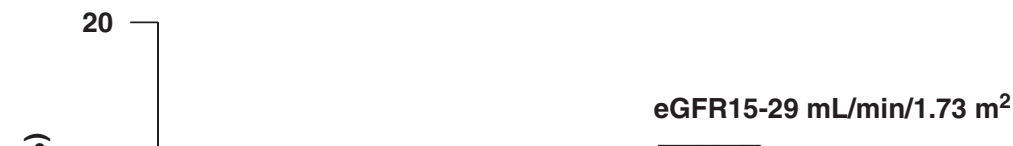

b

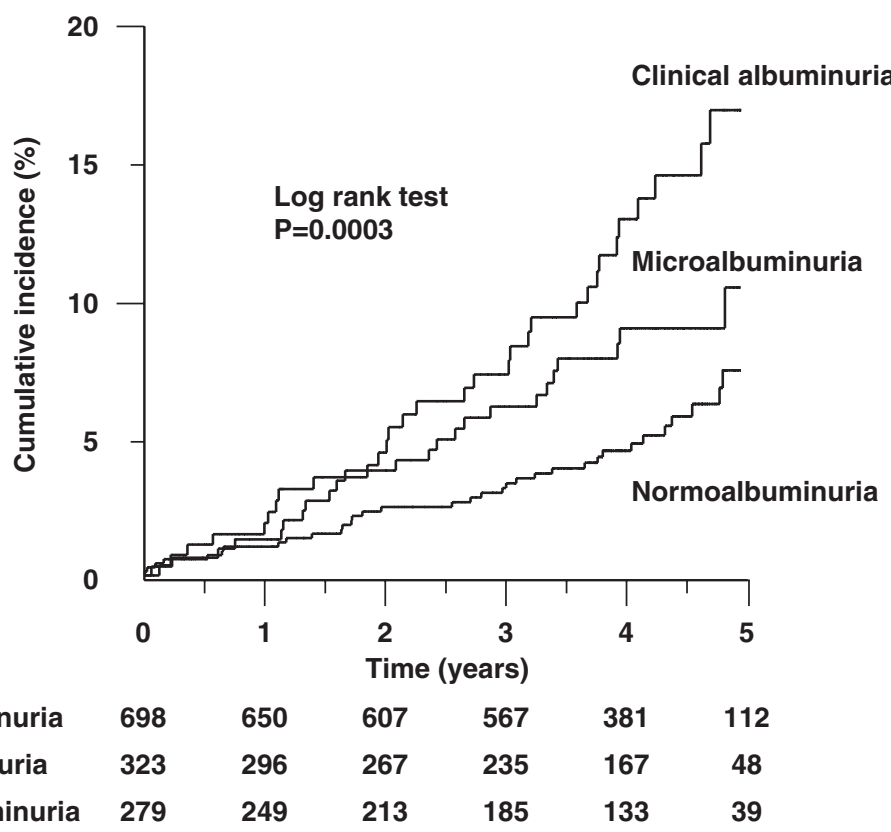

Figure 1 Kaplan-Meier curve of the cumulative incidence of first stroke events in type 2 diabetic patients stratified by estimated glomerular filtration rate (eGFR) (a) and urinary albumin (b). Normoalbuminuria, urinary albumin-to-creatinine ratio <30; microalbuminuria, 30-299; clinical albuminuria, $\geqslant 300$ mg per $\mathrm{g} \mathrm{Cr}$.

study of Japanese diabetic patients, we have shown that reduced eGFR is potentially associated with a higher risk of incident stroke in Japanese patients with T2DM; however, this association disappeared after adjusting for urinary ACR. In contrast, albuminuria, another renal manifestation of diabetic kidney disease, was a significant predictor of stroke events, even after adjusting for covariates such as eGFR.

In the recently published post hoc analyses from the Antihypertensive and Lipid-lowering Treatment to Prevent Heart Attack Trial $(\text { ALLHAT) })^{16}$ and the PROspective pioglitAzone Clinical Trial In macroVascular Events (PROactive), ${ }^{17}$ more diabetic patients with
CKD defined as having a reduced GFR, reached the primary composite cardiovascular end point than did patients without CKD. Unfortunately, the two studies lacked data regarding albuminuria/ proteinuria, thereby limiting the understanding of the independent effect of reduced GFR. In addition, these clinical trials originally included both diabetic and non-diabetic individuals carrying a high cardiovascular risk. In contrast, our study included diabetic patients who had no history of stroke events, presumably yielding conflicting results in terms of the effect of GFR.

Post hoc analyses from the Irbesartan in Diabetic Nephropathy Trial (IDNT), ${ }^{18}$ the Losartan Intervention For Endpoint reduction in 
a
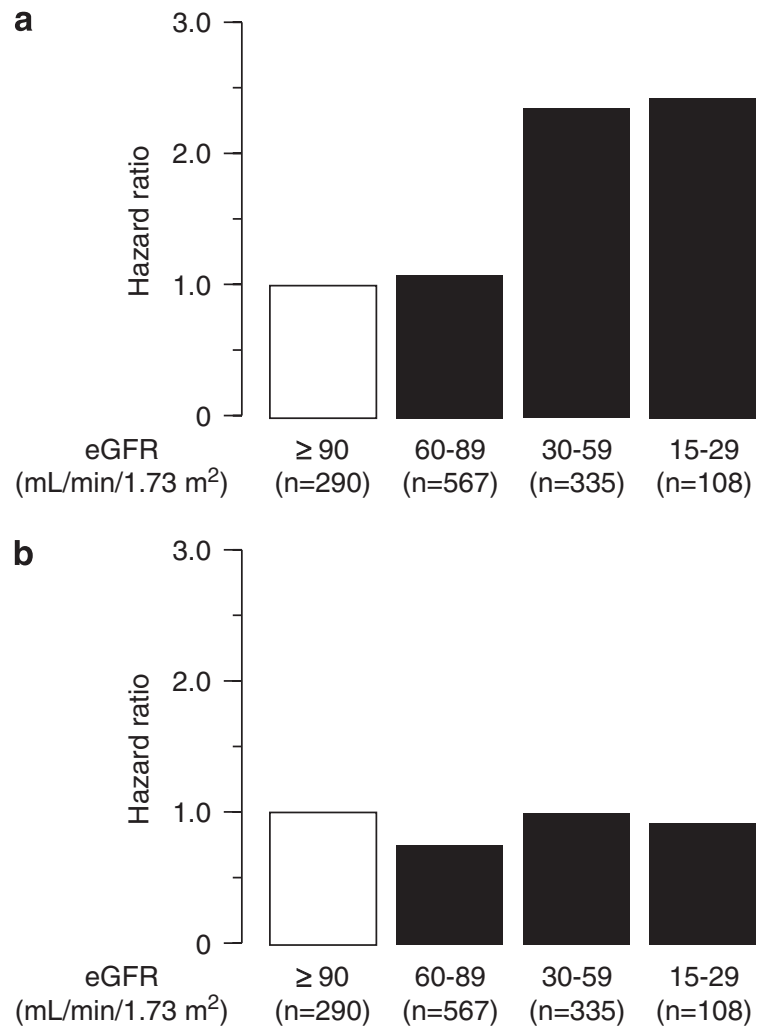

Figure 2 Hazard ratio of stroke in patients with type 2 diabetes in the univariate (a) and multivariate (b) Cox model stratified by eGFR levels (eGFR $\geqslant 90$ versus eGFR $60-89,30-59$ and $15-29 \mathrm{ml} \mathrm{min}^{-1}$ per $1.73 \mathrm{~m}^{2}$ ). The multivariate model included the following covariates: age, gender, body mass index, family history of stroke, smoking status, systolic blood pressure, diastolic blood pressure, duration of diabetes, proliferative retinopathy, hemoglobin A1C, logarithmically transformed triglyceride, high-density lipoprotein cholesterol, low-density lipoprotein cholesterol, logarithmically transformed C-reactive protein, use of renin-angiotensin system blockers, antiplatelet medication and a logarithmically transformed urinary albuminto-creatinine ratio.

hypertension (LIFE) and the Reduction of Endpoints in NIDDM with the Angiotensin II Receptor Antagonist Losartan (RENAAL) studies, ${ }^{19}$ as well as a population-based study from Hong Kong, ${ }^{9}$ showed that both albuminuria and decreased values of GFR (or increased serum creatinine levels) were associated with a higher risk of composite cardiovascular end points in patients with T2DM. In these studies, however, the effects of renal parameters on the end point limited to stroke events were not determined.

The reason for the lack of association between reduced GFR and stroke is unclear. One possible explanation may be related to the heterogeneous pathogenesis of strokes. Most stroke cases are commonly classified as a brain hemorrhage, a subarachnoid hemorrhage or a brain infarction..$^{20}$ Brain infarctions are clinically subcategorized as atherothrombotic, cardioembolic and lacunar infarctions. ${ }^{20} \mathrm{~A}$ recent study did not find a significant association between serum creatinine and lacunar infarction. ${ }^{21}$ Almost half of the ischemic stroke cases were lacunar infarctions in our study, possibly attenuating the impact of eGFR on incident strokes. In addition, the smaller sample size in our study may limit the examination of the impact on each stroke subtype.

In contrast to reduced eGFR, clinical albuminuria was confirmed to be a strong and independent predictor of stroke events in our study
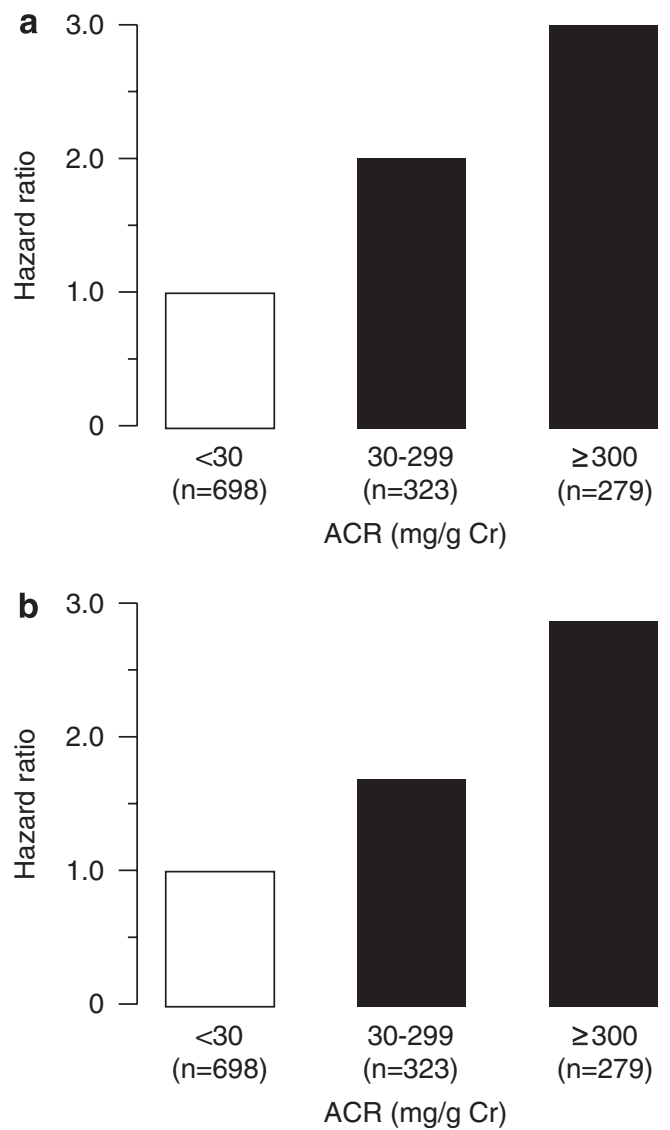

Figure 3 Hazard ratio of stroke in patients with type 2 diabetes in the univariate (a) and multivariate (b) Cox model stratified by urinary albuminto-creatinine ratio. The multivariate model included the aforementioned covariates (see legend for Figure 2), but used eGFR instead of the urinary albumin-to-creatinine ratio.

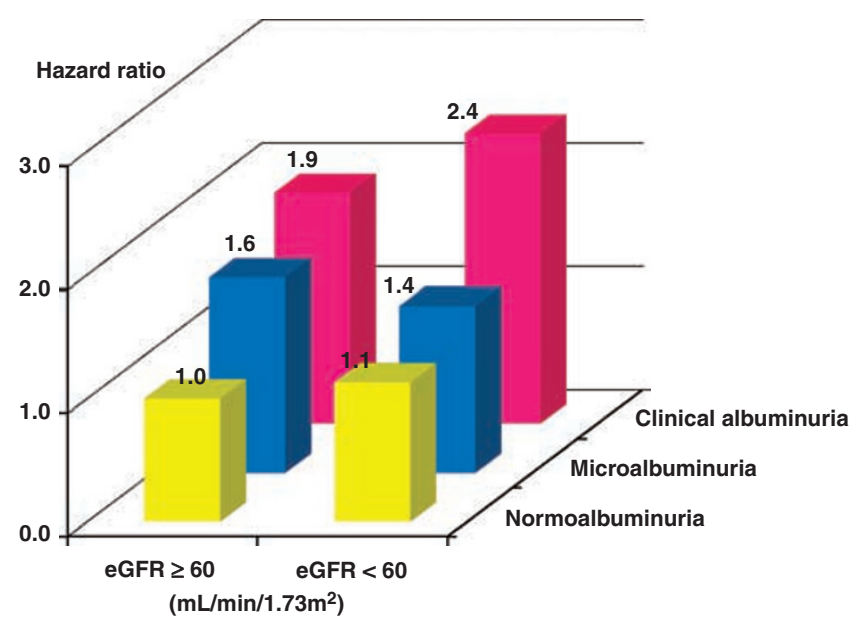

Figure 4 Hazard ratio of stroke for patients with type 2 diabetes in the multivariate model in six groups classified according to eGFR levels of $\geqslant 60 \mathrm{mlmin}^{-1}$ per $1.73 \mathrm{~m}^{2}$ or less and the degree of albuminuria. The multivariate model included the aforementioned covariates (see legend for Figure 2), excluding the eGFR and the urinary albumin-to-creatinine ratio.

cohort and of overall cardiovascular disease in earlier studies. ${ }^{9,18,19,22-24}$ Albuminuria is a marker of renal and systemic vascular damage ${ }^{25}$ that is associated with hypertension, ${ }^{26}$ dyslipidemia ${ }^{27}$ and obesity. ${ }^{28} \mathrm{We}$ 
have shown earlier that albuminuria, but not a decreased eGFR, is independently associated with metabolic syndrome or abdominal obesity. ${ }^{29}$ As the potency of albuminuria was maintained even after adjusting for these conventional risk factors in this study, nontraditional risk factors may serve as confounding factors. These may include inflammatory ${ }^{30}$ and thrombogenic factors, ${ }^{31}$ oxidative stress, homocysteine ${ }^{32}$ and asymmetric dimethylarginine (ADMA), ${ }^{33}$ all of which have been found to be associated with (micro)albuminuria in diabetic patients. A recent study has suggested that albuminuria, but not eGFR, was associated with arterial remodeling. This explains, at least in part, why albuminuria presents a greater risk of stroke. ${ }^{34}$

Our study has several limitations. First, this study was a hospitalbased study, yielding a selection bias. Second, we studied only diabetic patients without earlier history of stroke to determine the effects of renal parameters in patients with T2DM on the first stroke event. Our results should therefore, be reviewed with caution when extrapolating the incidence of a secondary stroke event. Finally, albuminuria was determined from a single measurement of urinary ACR, possibly leading to improper categorization because of a marked day-to-day variability in albumin excretion. Although we did not obtain multiple measurements of urinary ACR, we restricted the timing of urine collection to the first morning to minimize exercise-induced and diurnal variation. ${ }^{35}$

In conclusion, our prospective hospital-based observational cohort study provides evidence that association between reduced eGFR and a higher risk of incident stroke observed in patients with T2DM may be due to underlying increases in albuminuria. The effects of albuminuria and eGFR on each stroke subtype and their ability to predict CAD, the other major cardiovascular event in patients with T2DM, remains to be elucidated.

\section{CONFLICT OF INTEREST}

The authors declare no conflict of interest.

1 Kidney Disease Outcome Quality Initiative. K/DOQI clinical practice guidelines for chronic kidney disease: evaluation, classification, and stratification. Am J Kidney Dis 2002; 39 (Suppl 2): S1-S246.

2 Ninomiya T, Kiyohara Y, Kubo M, Tanizaki Y, Doi Y, Okubo K, Wakagawa Y, Hata J, Oishi Y, Shikata K, Yonemoto K, Hirakata H, lida M. Chronic kidney disease and cardiovascular disease in a general Japanese population: The Hisayama Study. Kidney Int 2005; 68: 228-236.

3 Go AS, Chertow GM, Fan D, McCulloch CE, Hsu CY. Chronic kidney disease and the risks of death, cardiovascular events, and hospitalization. N Engl J Med 351; 2004: 1296-1305.

4 Keith DS, Nichols GA, Vullion CM, Brown JB, Smith DH. Longitudinal follow-up and outcomes among general population with chronic kidney disease in a large managed care organization. Arch Intern Med 2004; 164: 659-663.

5 Murray CJL, Lopez AD. Global Pattern of Cause of Death and Burden of Disease in 1990, with Projection to 2020_Investigating in Health Research and Development: Report of the Ad Hoc Committee on Health Research Relating to Future Intervention Options. WHO: Geneva, 1996.

6 Menotti A, Jacobs Jr DR, Blackburn H, Kromhout D, Nissine A, Nedeljkovic S, Buzina R, Mohacek I, Seccareccia F, Giampaoli S, Dontas A, Aravanis C, Toshima H. Twentyfive-year prediction of stroke deaths in the seven countries study: the role of blood pressure and its change. Stroke 1996; 27: 381-387.

7 Mulnier HE, Seaman HE, Raleigh VS, Soedamah-Muthu SS, Colhoun HM, Lawrenson RA, De Vries CS. Risk of stroke in people with type 2 diabetes in the UK: a study using the General Practice Research Database. Diabetologia 2006; 49: 2859-2865.

8 Wolf PA, D'Agostino RB, Belanger AJ, Kannel WB. Probability of stroke: a risk profile from the Framingham Study. Stroke 1991; 22: 312-318.

9 So WY, Kong AP, Ma RC, Ozaki R, Szeto CC, Chan NN, Ng V, Ho CS, Lam CW, Chow CC, Cockram CS, Chan JC, Tong PC. Glomerular filtration rate, cardiorenal endpoints, and all-cause-mortality in type 2 diabetic patients. Diabetes Care 2006; 29: 2046-2052.

10 Alberti KGMM, Zimmet P, for the WHO consultation. Definition, diagnosis, and classification of diabetes mellitus and its complications, part 2: diagnosis and classification of diabetes mellitus provisional report of a WHO consultation. Diabet Med 1998; 15: 539-553.

11 Hirsch AT, Haskal ZJ, Hertzer NR, Bakal CW, Creager MA, Halperin JL, Hiratzka LF, Murphy WRC, Olin JW, Puschett JB, Rosenfield KA, Sacks D, Stanley JC, Taylor Jr LM, White CJ, White J, White RA. ACC/AHA 2005 practice guidelines for the management of patients with peripheral arterial disease (lower extremity, renal, mesenteric, and abdominal aortic). Circulation 2006; 113: e436-e465.

12 Levey AS, Coresh J, Greene T, Stevens LA, Zhang YL, Hendriksen S, Kusek JW, Van Lente F. Using standardized serum creatinine values in the modification of diet in renal disease study equation for estimating glomerular filtration rate. Ann Intern Med 2006; 145: 247-254

13 Imai E, Horio M, Nitta K, Yamagata K, Iseki K, Tsukamoto Y, Ito S, Makino H, Hishida A, Matsuo S. Modification of the Modification of Diet in Renal Disease (MDRD) Study equation for Japan. Am J Kidney Dis 2007; 50: 927-937.

14 American Diabetes Association. Nephropathy in diabetes. Diabetes Care 2004; 322 : 531-536.

15 Weiner DE, Tighiouart H, Amin MG, Stark PC, MacLeod B, Griffith JL, Salem DN, Levey AS, Sarnak MJ. Chronic kidney disease as a risk factor for cardiovascular disease and all-cause mortality: a pooled-analysis of community-based studies. J Am Soc Nephrol 2004; 15: 1307-1315.

16 Rahman M, Pressel S, Davis BR, Nwachuku C, Wright Jr JT, Whelton PK, Barzilay J, Batuman V, Eckfeldt JH, Farber MA, Franklin S, Henriquez M, Kopyt N, Louis GT, Saklayen M, Stanford C, Walworth C, Ward H, Wiegmann T, ALLHAT Collaborative Research Group. Cardiovascular outcomes in high-risk hypertensive patients stratified by baseline glomerular filtration rate. Ann Intern Med 2006; 144: 172-180.

17 Schneider CA, Ferrannini E, Defronzo R, Schernthaner G, Yates J, Erdmann E. Effect of pioglitazone on cardiovascular outcome in diabetes and chronic kidney disease. J Am Soc Nephrol 2008; 19: 182-187.

18 Anavekar NS, Gans DJ, Berl T, Rohde RD, Cooper W, Bhaumik A, Hunsicker LG, Rouleau JL, Lewis JB, Vanhille P, Locatelli F, Goldhaber S, Lewis EJ, Pfeffer MA. Predictors of cardiovascular events in patients with type 2 diabetic nephropathy and hypertension: a case for albuminuria. Kidney Int 2004; 92: S50-S55.

19 Eijkelkamp WB, Zhang Z, Brenner BM, Cooper ME, Devereux RB, Dahlöf B, Ibsen H, Keane WF, Lindholm LH, Olsen MH, Parving HH, Remuzzi G, Shahinfar S, Snapinn SM, Wachtell K, de Zeeuw D. Renal function and risk for cardiovascular events in type 2 diabetic patients with hypertension: the RENAAL and LIFE studies. J Hypertens 2007; 25: 871-876.

20 Special Report From the National Institute of Neurological Disorders and Stroke. Classification of cerebrovascular diseases III. Stroke 1990; 21: 637-676.

21 Cohen AB, Taylor RA, Steven R, Messé SR, Kasner SE. Serum creatinine does not improve early classification of ischemic stroke caused by small artery occlusion. J Stroke Cerebrovasc Dis 2006; 15: 96-100.

22 Dinneen SF, Gerstein HC. The association of microalbuminuria and mortality in noninsulin-dependent diabetes mellitus: a systematic overview of the literature. Arch Intern Med 1997; 157: 1413-1418.

23 Neamer NB, Coull BM, Clark WM, Wynn M. Microalbuminuria in ischemic stroke. Arch Neurol 1999; 56: 699-702.

24 Yuyun MF, Khaw KT, Luben R, Welch A, Bingham S, Day NE, Wareham NJ. Microalbuminuria and stroke in a British population: the European Prospective Investigation into Cancer in Norfolk (EPIC-Norfolk) population study. J Intern Med 2004; 255: 247-255.

25 Paisley KE, Beaman M, Tooke JE, Mohamed-Ali V, Lowe GD, Shore AC. Endothelial dysfunction and inflammation in asymptomatic proteinuria. Kidney Int 2003; 63 : 624-633.

26 Bianchi S, Bigazzi R, Campese VM. Microalbuminuria in essential hypertension: significance, pathophysiology, and therapeutic implications. Am J Kidney Dis 1999; 34: 973-995.

27 Shankar A, Klein R, Moss SE, Klein BE, Wong TY. The relationship between albuminuria and hypercholesterolemia. J Nephrol 2004; 17: 658-665.

28 Chen J, Muntner P, Hamm LL, Jones DW, Batuman V, Fonseca V, Whelton PK, He J. The metabolic syndrome and chronic kidney disease in US adults. Ann Intern Med 2004; 140: $167-174$

29 Hanai K, Babazono T, Iwamoto Y. Renal manifestations of metabolic syndrome in type 2 diabetes. Diabetes Res Clin Pract 2008; 79: 318-324.

30 Fenq L, Matsumoto C, Schwartz A, Schmidt DM, Pile-Spellman J. Chronic vascular inflammation in patients with type 2 diabetes: endothelial biopsy and RT-PCR analysis. Diabetes Care 2005; 28: 379-384.

31 Juhan-Vague I, Alessi MC, Vague P. Thrombogenic and fibrinolytic factors and cardiovascular risk in non-insulin-dependent diabetes mellitus. Ann Med 1996; 28 : 371-380.

32 Soinio M, Marniemi J, Laakso M, Lehto S, Rönnemaa T. Elevated plasma homocysteine level is an independent predictor of coronary heart disease events in patients with type 2 diabetes mellitus. Ann Intern Med 2004; 140: 94-100.

33 Fliser D, Kronenberg F, Kielstein JT, Morath C, Bode-Boger SM, Haller H, Ritz E. Asymmetrical dimethylarginine and progression of chronic kidney disease: the mild to moderate kidney disease study. J Am Soc Nepnrol 2005; 16: 2456-2461.

34 Hermans MM, Henry RM, Dekker JM, Nijpel G, Heine RJ, Stehouwer CD. Albuminruia, but not estimated glomerular filtration rate, is associated with maladaptive arterial remodeling: the Hoorn Study. J Hypertens 2008; 26: 791-797.

35 Babazono T, Takahashi C, Iwamoto Y. Definition of microalbuminuria in first-morning and random spot urine in diabetic patients. Diabetes Care 2004; 27: 1838-1839. 